\title{
o-Aminothiophenol in Reactions with Carbonyl Compounds and Isocyanides: a Word of Caution
}

\author{
Sergey Tsirulnikov, ${ }^{a, b}$ Dmitry Dmitriev, ${ }^{b}$ and Mikhail Krasavin**a \\ a Science and Education Center “Innovative Research”, Yaroslavl State Pedagogical University, 150000, Russia \\ ${ }^{\mathrm{b}}$ Chemical Diversity Research Institute, 2a Rabochaya St., Khimki, Moscow Reg., 141400, Russia \\ Fax: +7(495)626-9780 \\ E-mail:myk@chemdiv.com
}

Received: The date will be inserted once the manuscript is accepted.

\begin{abstract}
The reaction of $o$-aminothiophenol with carbonyl compounds and $t$-BuNC was revisited and was shown to provide 1(1,3-benzothiazol-3(2H)-yl)methanimines 4 (not described hitherto) and not the earlier reported $4 H$-benzo[1,4]thiazine 5 . To isolate the latter using this reaction a due amount of caution and structure scrutiny is warranted. The basis for assignment of the products to both structural classes is provided.
\end{abstract}

Key words: isocyanide-based multi-component reactions, bifunctional reagents, isocyanide-intercepting nuceophiles, thiophenol, amidines.

Recently, we reported $^{1}$ on a new variant of an isocyanide-based multicomponent reaction (IMCR) of $o$ phenylenediamines with aldehydes and isocyanides leading to easily oxidized dihydroquinoxalines and, ultimately, providing a conceptually new route to quinoxalines (Scheme 1).

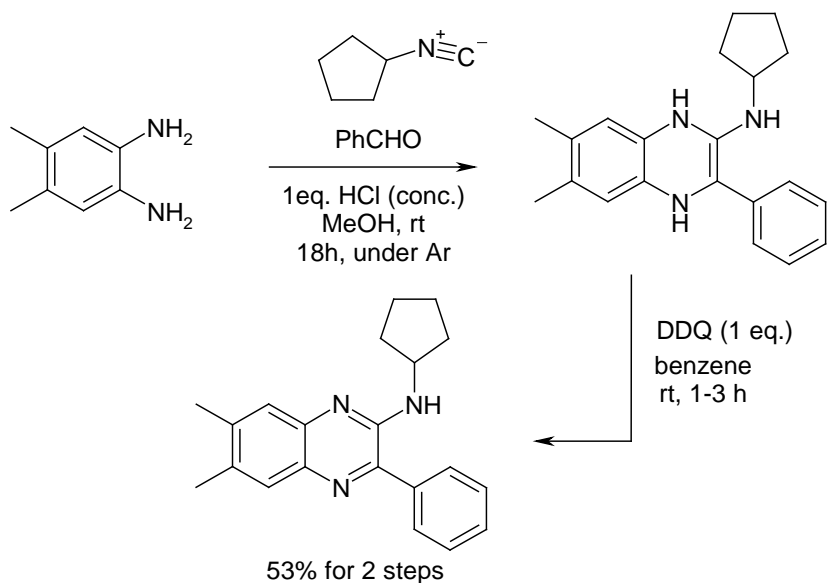

Scheme 1. IMCR of an o-phenylenediamine. ${ }^{1}$

This methodology has been recently extended by Kysil et $a .^{2}$ to include cyclic ketone components as well as [1,2,5] oxadiazole-3,4-diamine under reaction conditions including TMSCl as the promoter. In addition, similar reactions involving 1,2-diamines have also been published. ${ }^{3,4}$ In all of these transformations, the diamines act as bifunctional reagents providing both the amine component to form the Schiff base adduct with the carbonyl compound and an isocyanide-intercepting $N$-nucleophile (Scheme 2).

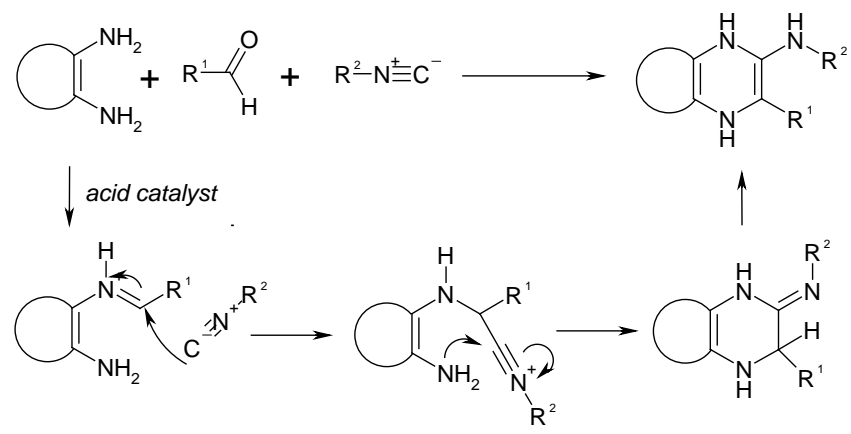

Scheme 2. Plausible mechanism for IMCR of 1,2-diamines.

We also tested $o$-aminothiophenol under the reaction conditions depicted in Scheme 1, aiming to verify if the respective 3-aryl-4H-benzo[1,4]thiazine-2-amine $\mathbf{1}$ would form. However, this attempt only resulted in a complex mixture of products, one of which could be identified as 2 , i. e. the products of Ugi reaction involving water $^{5}$ as isocyanide-intercepting nucleophile (Scheme 3).<smiles>CC(C)(C)NC1=C(c2ccccc2)Nc2ccccc2S1</smiles>

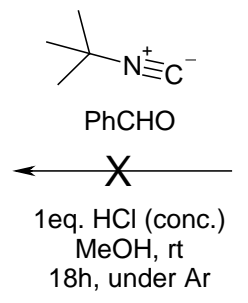<smiles>Nc1ccccc1S</smiles>
$\mathrm{MeOH}, \mathrm{rt}$ 18h, under Ar

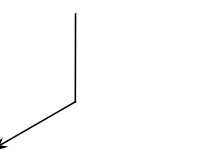

Scheme 3. Attempted IMCR of $o$-aminothiophenol.

Our interest to the reaction of $o$-aminothiophenol has been refueled by a publication ${ }^{6}$ reporting on a facile and high-yielding preparation of compounds related to $\mathbf{1}$. According to this article, compound $\mathbf{1}$ was formed in 89\% isolated yield (along with 11 other examples) upon mixing all three components in ethanol and heating the 
solution at reflux for $5 \mathrm{~h}$ in presence of $p$-toluenesulfonic acid (Scheme 4). Although in our hands, the outcome of this reaction was similar to the one presented in Scheme 3 , we decided to test it under TMSCl-promoted conditions. $^{2}$

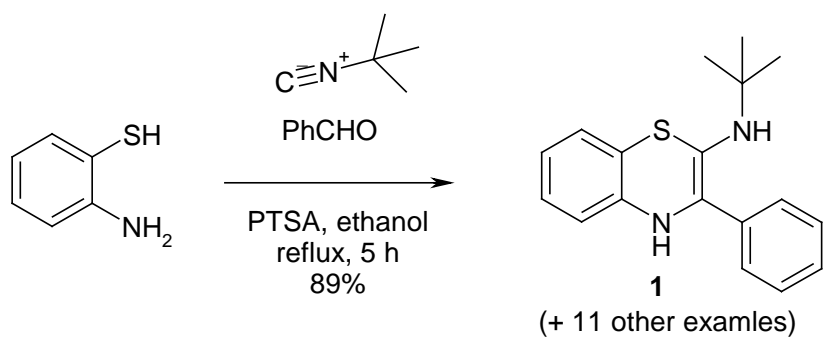

Scheme 4. Reported preparation of 3-aryl-4H-benzo[1,4]thiazine-2amine $\mathbf{1}^{6}$

Simple mixing of $o$-aminothiophenol an aromatic aldehyde and $t$-BuNC with TMSCl (1.0 eq.) in methanol and heating the reaction mixture at reflux for $12 \mathrm{~h}$ again provided a complex mixture of products. This was entirely in accordance with the earlier observations made for 1,2-diamines ${ }^{2}$ that pre-formation of an aminal adduct with the carbonyl compound is critical for a successful IMCR. Therefore, in all our subsequent experiments we used 2,3-dihydro-1,3-benzothiazoles $\mathbf{3}$ (as confirmed by NMR experiments) prepared by reacting equimolar amounts of $o$-aminothiophenol with aldehydes or ketones, without further purification.

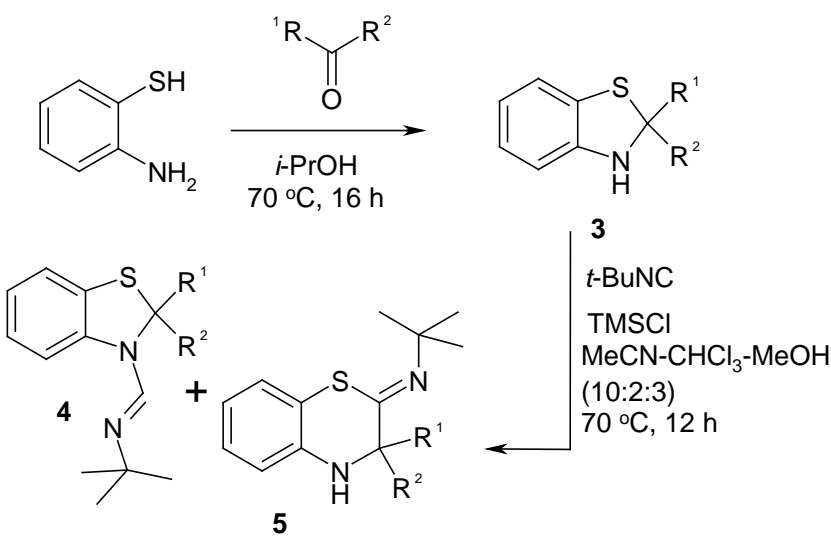

Scheme 5. IMCR of $o$-aminothiophenol investigated in this work.

Ten 2,3-dihydro-1,3-benzothiazoles 3a-j were prepared and reacted with $t$-BuNC in the presence of TMSCl $(1.0$ eq.). Contrary to the expectations, in all cases the major component of the product mixture (according to ${ }^{1} \mathrm{H}$ NMR analysis of the crude product) was 1-(1,3benzothiazol-3(2H)-yl)methanimine 4 and not the $4 H_{-}$ benzo[1,4]thiazine 5 (Scheme 5). In fact, in all reactions except those with $\mathbf{3 a}, \mathbf{3 b}$ and $\mathbf{3 e}$, the latter product was detected in negligible amount that did not warrant isolation. Accordingly, the products $\mathbf{4 a - j}$ and $\mathbf{5 a , b}, \mathbf{e}$ were isolated in low to moderate yields (Table 1 ) by column chromatography and characterized.?
Table 1. Compounds 4 - 5 prepared via IMCR of $o$-aminothiophenol.

\begin{tabular}{|c|c|c|c|c|c|}
\hline Entry & $\begin{array}{l}\text { Com- } \\
\text { pound }\end{array}$ & $\mathrm{R}^{1}$ & $\mathrm{R}^{2}$ & $\begin{array}{c}\text { Yield } \\
\text { of } 4 \\
(\%)\end{array}$ & $\begin{array}{l}\text { Yield } \\
\text { of } 5 \\
(\%)\end{array}$ \\
\hline 1 & $3-5 a$ & \multicolumn{2}{|c|}{$-\left(\mathrm{CH}_{2}\right)_{5-}^{-}$} & 66 & 12 \\
\hline 2 & $3-5 b$ & \multicolumn{2}{|c|}{$-\left(\mathrm{CH}_{2}\right)_{4^{-}}$} & 45 & 38 \\
\hline 3 & $3-5 c$ & \multicolumn{2}{|c|}{$-\left(\mathrm{CH}_{2}\right)_{2}-\mathrm{O}-\left(\mathrm{CH}_{2}\right)_{2}-$} & 54 & -- \\
\hline 4 & 3-5d & \multicolumn{2}{|c|}{$-\left(\mathrm{CH}_{2}\right)_{2}-\mathrm{N}(\mathrm{Ac})-\left(\mathrm{CH}_{2}\right)_{2^{-}}$} & 43 & -- \\
\hline 5 & $3-5 e$ & \multicolumn{2}{|c|}{$-\left(\mathrm{CH}_{2}\right)_{2}-\mathrm{CH}(t-\mathrm{Bu})-\left(\mathrm{CH}_{2}\right)_{2}-$} & 62 & 5 \\
\hline 6 & $3-5 f$ & $4-\mathrm{MeOC}_{6} \mathrm{H}_{4}$ & $\mathrm{H}$ & 70 & -- \\
\hline 7 & $3-5 g$ & $4-i-\mathrm{PrC}_{6} \mathrm{H}_{4}$ & $\mathrm{H}$ & 59 & -- \\
\hline 8 & $3-5 h$ & $2-\mathrm{MeC}_{6} \mathrm{H}_{4}$ & $\mathrm{H}$ & 48 & -- \\
\hline 9 & $3-5 i$ & $3-\mathrm{NCC}_{6} \mathrm{H}_{4}$ & $\mathrm{H}$ & 63 & -- \\
\hline 10 & $3-5 j$ & $3,4-\mathrm{Me}_{2} \mathrm{C}_{6} \mathrm{H}_{3}$ & $\mathrm{H}$ & 64 & -- \\
\hline
\end{tabular}

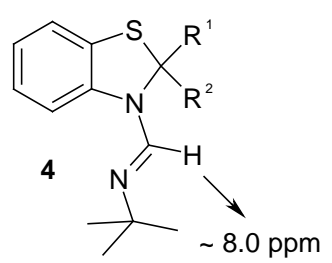<smiles>[R]C1([R])C(=NC(C)(C)C)Sc2ccccc2N1CCOC</smiles>

Figure 1. Characteristic signals in the ${ }^{1} \mathrm{H}$ NMR spectra of $\mathbf{4}$ and $\mathbf{5}$.

The products $\mathbf{4}$ and $\mathbf{5}$ are isomers that can be distinguished by characteristic signals in their ${ }^{1} \mathrm{H}$ NMR spectra corresponding to the amidine $\mathrm{C}-\mathrm{H}$ proton and the thiazine N-H proton, respectively (Fig. 1). Such structural assignment was further confirmed by single-crystal Xray analysis ${ }^{8}$ obtained for $\mathbf{4 f}$ and $5 \mathbf{a}$ (Fig. 2).

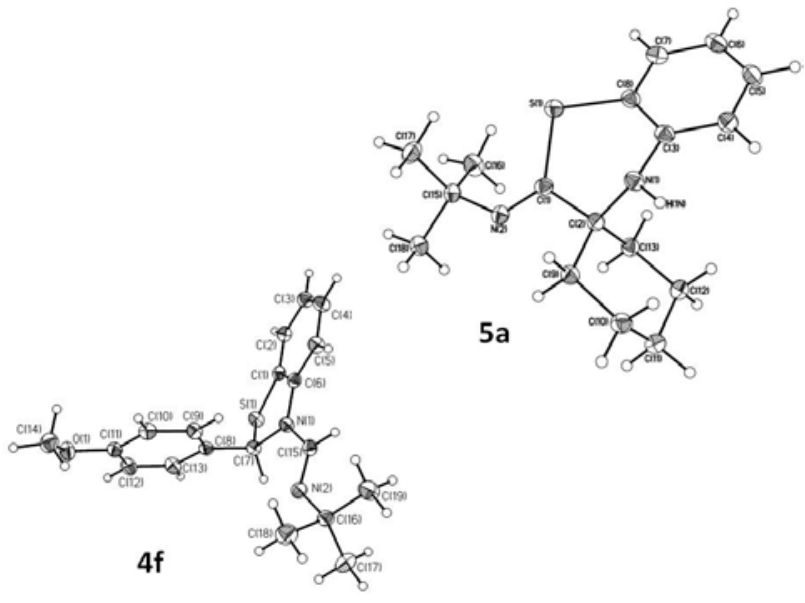

Figure 2. X-ray structures of $\mathbf{4 f}$ and $\mathbf{5 a}$.

The unexpected formation of 1-(1,3-benzothiazol-3(2H)yl)methanimines $\mathbf{4}$ was likely due to the ability of isocyanides to form amidines via a direct, Lewis acidcatalyzed reaction with amines (in this case, the secondary aniline 3). This is a less studied yet not unprecedent$\mathrm{ed}^{9}$ reactivity of isocynides. 
Using 2,3-dihydro-1,3-benzothiazole $\mathbf{3 b}$, for which the formation of the respective $4 H$-benzo[1,4]thiazine $\mathbf{5 b}$ was most pronounced, we screened a small set of Lewis and Brønsted acids (in catalytic to equimolar quantities, in compatible solvents) while monitoring the ratio of the characteristic signals corresponding to the products $\mathbf{4 b}$ and $\mathbf{5 b}$ in the ${ }^{1} \mathrm{H}$ NMR spectrum of the crude reaction mixture. As can be seen from Table 2, despite the initial promise of improvement (entries 1 and 7) or even reversal (entries 2 and 6) of the $\mathbf{4 b}: 5 \mathbf{b}$ ratio from the ${ }^{1} \mathrm{H}$ NMR data, the isolated yields of $\mathbf{5 b}$ were still highest when TMSCl was used as a promoter (and optimal in $\mathrm{MeOH}-$ $\mathrm{CHCl}_{3}$ solvent system), due to noticeable formation of unidentified polymeric by-products in all other cases.

Table 2. Acid promoter screening for the reaction of $\mathbf{3 b}$ with $t$-BuNC.

\begin{tabular}{|l|l|l|l|}
\hline Entry & Acid promoter & $\begin{array}{l}\text { Ratio } \mathbf{4 b}: 5 \mathbf{b} \\
\text { by crude }{ }^{1} \mathrm{H} \\
\text { NMR }\end{array}$ & $\begin{array}{l}\text { Isolated } \\
\text { yield of } \\
\mathbf{5 b} \text { (\%) }\end{array}$ \\
\hline 1 & TsOH, 1.0 eq./MeCN & $2: 3$ & $<10$ \\
\hline 2 & Yb(OTf $)_{3}, 0.2$ eq./MeCN & $1: 3$ & 12 \\
\hline 3 & $\mathrm{HCl}, 1.0$ eq./dioxane, $3 \mathrm{M}$ & $9: 1$ & $\begin{array}{l}\text { not } \\
\text { isolated }\end{array}$ \\
\hline 4 & TMSCl, 1.0 eq./MeCN & $3: 1$ & 29 \\
\hline $5^{a}$ & $\begin{array}{l}\text { TMSCl, } 1.0 \text { eq./MeCN- } \\
\text { MeOH-CHCl }(10: 3: 2)\end{array}$ & $3: 2$ & 41 \\
\hline 6 & $\mathrm{Sc}(\mathrm{OTf})_{3}, 0.2$ eq./ MeCN & $1: 3$ & 15 \\
\hline 7 & TsOH, 0.3 eq./EtOH & $1: 1$ & $<10$ \\
\hline${ }^{a} \mathrm{Re}-\mathrm{run}$ of the entry 2 Table 1.
\end{tabular}

${ }^{a}$ Re-run of the entry 2, Table 1.

Extending the time of TMSCl activation of 3 prior to $t$ BuNC addition to 40 min did not change the ratio of $4: 5$ for entries 2-4 and 6-10 (Table 1). However, it slightly improved for entries 1 (from 4:1 to 7:3) and 5 (from 9:1 to $4: 1$ ) and the corresponding $4 H$-benzo[1,4]thiazines $\mathbf{5 a}$ and 5e were isolated in $26 \%$ and $14 \%$ yield, respectively.

In conclusion, we have revisited the reaction of $o$ aminothiophenol with carbonyl compounds and $t$-BuNC and established that, under Lewis and Brønsted acid catalysis (especially, TMSCl) the major product is the previously unreported 1-(1,3-benzothiazol-3(2H)yl)methanimine 4 and not the earlier reported $4 H-$ benzo[1,4]thiazine $\mathbf{5}$. To isolate the latter using this reaction, a due amount of caution and structure scrutiny is warranted.

Typical procedure 1. Synthesis of 4: A thoroughly degassed solution of $o$-aminothiophenol ( $3 \mathrm{mmol}$ ) and the carbonyl compound (3 mmol) in isopropyl alcohol (3 $\mathrm{mL}$ ) was heated at $70{ }^{\circ} \mathrm{C}$ for $16 \mathrm{~h}$. The solvent was removed in vacuo and the residue was re-dissolved in anhydrous MeCN (10 mL). A solution of TMSCl (3 mmol) in chloroform $(2 \mathrm{~mL})$ was added followed by a solution of $t$-BuNC in $\mathrm{MeOH}(3 \mathrm{~mL})$. The resulting mixture was heated at $70{ }^{\circ} \mathrm{C}$ for $12 \mathrm{~h}$, cooled to r. t., evaporated to dryness and the residue was dispersed in water $(20 \mathrm{~mL})$. The resulting suspension was basified with aq. $\mathrm{NaOH}$ and extracted with chloroform ( $3 \times 30 \mathrm{~mL}$ ). The combined organic extracts were dried over anhydrous $\mathrm{Na}_{2} \mathrm{SO}_{4}$, filtered and concentrated. The crude products was purified by column chromatography on basic alumina using $0 \rightarrow 2.5 \% \mathrm{MeOH}$ in $\mathrm{CH}_{2} \mathrm{Cl}_{2}$ as eluent.
Typical procedure 2. Synthesis of 5: To prepare these compounds, the same procedure was used but the time prior to the addition of $t$-BuNC was extended to $40 \mathrm{~min}$. A similar chromatographic isolation procedure was used, however, these products generally had higher $R_{f}$ values than 4.

\section{Acknowledgment}

This research was supported by the Federal Agency for Science and Innovation (Russian Federation Government Contract 02.740.11.0092). Dr. Alexander Manaev of Chemical Diversity Research Institute is acknowledged for his help in obtaining X-ray structures.

\section{References and notes}

(1) Krasavin, M.; Parchinsky, V. Synlett 2008, 645-648.

(2) Kysil, V.; Khvat, A.; Tsirulnikov, S.; Tkachenko, S.; Williams, C.; Churakova, M.; Ivachtchenko, A. Eur. J. Org. Chem. 2010, 1525-1543.

(3) Shaabani, A.; Maleki, A.; Moghimi-Rad, J. J. Org. Chem. 2007, 72, 6309-6311.

(4) Heravi, M. M.; Baghernejad, B.; Oskooie, H. A. Tetrahedron Lett. 2009, 50, 767-769.

(5) Ugi, I.; Steinbrückner, C. Chem. Ber. 1961, 94, 734-742.

(6) Heravi, M. M.; Baghernejad, B.; Oskooie, H. A. Synlett 2009, 1123-1125.

(7) Characterization data for selected compounds: 5a: Emerald green solid, $\mathrm{mp}=172{ }^{\circ} \mathrm{C}$ (decomp.). ${ }^{1} \mathrm{H}$ NMR $(500 \mathrm{MHz}$, DMSO- $_{6}$ ) $\delta 6.95-7.07$ (m, 3H), $6.71(\mathrm{td}, J=7.6 \mathrm{~Hz}, J=$ $1.3 \mathrm{~Hz}, 1 \mathrm{H}), 5.78$ (s, $1 \mathrm{H}), 1.63-1.78$ (m, 2H), 1.42-1.56 (m, 7H), 1.33 (s, 9H), 1.12-1.27 (m, 1H). ${ }^{13} \mathrm{C}$ NMR (125 MHz, DMSO- $\left.d_{6}\right) \delta 156.2,140.9,126.2,125.0,118.9,118.8$, 117.2, 57.3, 55.3, 33.0, 28.6, 25.4, 21.0. LC MS m/z 289 $(\mathrm{M}+\mathrm{H})$. Anal. calcd for $\mathrm{C}_{17} \mathrm{H}_{24} \mathrm{~N}_{2} \mathrm{~S}: \mathrm{C}, 70.79 \mathrm{H}, 8.39$; N, 9.71. Found: C, 70.72 H, 8.48; N, 9.83. 5b: Brown solid, $\mathrm{mp}=169-172{ }^{\circ} \mathrm{C}$ (broad). ${ }^{1} \mathrm{H}$ NMR (500 MHz, DMSO- $\left.d_{6}\right)$ $\delta 7.05$ (d, $J=7.6 \mathrm{~Hz}, 1 \mathrm{H}), 6.97$ (t, $J=7.6 \mathrm{~Hz}, 1 \mathrm{H}), 6.87$ (d, $J=7.6 \mathrm{~Hz}, 1 \mathrm{H}), 6.70$ (t, $J=7.6 \mathrm{~Hz}, 1 \mathrm{H}), 6.05(\mathrm{~s}, 1 \mathrm{H}), 2.01-$ 2.14 (m, 2H), 1.43-1.73 (m, 6H), 1.33 (s, 9H). ${ }^{13} \mathrm{C}$ NMR $\left(125 \mathrm{MHz}, \mathrm{DMSO}-d_{6}\right) \delta 156.0,142.7,126.3,125.3,118.8$, 116.8, 67.7, 55.0, 36.4, 28.7, 23.6. LCMS m/z 275 (M+H). Anal. calcd for $\mathrm{C}_{16} \mathrm{H}_{22} \mathrm{~N}_{2} \mathrm{~S}$ : C, $70.03 \mathrm{H}, 8.08 ; \mathrm{N}, 10.21$. Found: C, 69.89 H, 8.01; N, 10.13. 5e: Brown solid, mp = $186{ }^{\circ} \mathrm{C}$ (decomp.). Single diastereomer! ${ }^{1} \mathrm{H}$ NMR (500 MHz, DMSO-d 6 ) $\delta 6.98(\mathrm{~d}, J=7.6 \mathrm{~Hz}, 1 \mathrm{H}), 6.93(\mathrm{t}, J=7.6$ $\mathrm{Hz}, 1 \mathrm{H}), 6.82(\mathrm{~d}, J=7.6 \mathrm{~Hz}, 1 \mathrm{H}), 6.67(\mathrm{t}, J=7.6 \mathrm{~Hz}, 1 \mathrm{H})$, 5.77 (s, $1 \mathrm{H}), 2.07$ (d, $J=12.6 \mathrm{~Hz}, 2 \mathrm{H}), 1.54(\mathrm{~m}, 4 \mathrm{H}), 1.35$ (s, 9H), 1.15-1.25 (m, 2H), $1.00(\mathrm{~m}, 1 \mathrm{H}), 0.82(\mathrm{~s}, 9 \mathrm{H}) .{ }^{13} \mathrm{C}$ NMR (125 MHz, DMSO-d $\left.d_{6}\right) \delta 152.6,141.5,126.0,124.6$, 118.3, 117.6, 116.5, 56.5, 55.5, 46.9, 35.5, 32.1, 28.7, 27.3, 23.1. LCMS m/z $345(\mathrm{M}+\mathrm{H})$. Anal. calcd for $\mathrm{C}_{21} \mathrm{H}_{32} \mathrm{~N}_{2} \mathrm{~S}$ : C, 73.20 H, 9.36; N, 8.13. Found: C, 73.29 H, 9.49; N, 8.23. 4b: Brown oil. ${ }^{1} \mathrm{H}$ NMR (500 MHz, DMSO- $\left.d_{6}\right) \delta 7.98$ (s, $1 \mathrm{H}), 7.48(\mathrm{~d}, J=7.8 \mathrm{~Hz}, 1 \mathrm{H}), 7.10(\mathrm{~d}, J=7.8 \mathrm{~Hz}, 1 \mathrm{H})$, $6.98(\mathrm{t}, J=7.8 \mathrm{~Hz}, 1 \mathrm{H}), 6.82(\mathrm{t}, J=7.8 \mathrm{~Hz}, 1 \mathrm{H}), 2.76-2.92$ (m, 2H), 1.76-2.02 (m, 4H), 1.58-1.74 (m, 2H), 1.20 (s, 9H). ${ }^{13} \mathrm{C}$ NMR (125 MHz, DMSO-d $) \delta 141.8,141.4$, 125.2, 125.0, 121.7, 121.4, 111.4, 85.2, 54.6, 30.6, 23.6. LCMS m/z $275(\mathrm{M}+\mathrm{H})$. Anal. calcd for $\mathrm{C}_{16} \mathrm{H}_{22} \mathrm{~N}_{2} \mathrm{~S}$ : C, 70.03 H, 8.08; N, 10.21. Found: C, 70.12 H, 8.13; N, 10.30. 4c: Dark yellow solid, $\mathrm{mp}=182-184{ }^{\circ} \mathrm{C}$. ${ }^{1} \mathrm{H}$ NMR $\left(500 \mathrm{MHz}\right.$, DMSO- $\left.d_{6}\right) \delta 8.01(\mathrm{~s}, 1 \mathrm{H}), 7.59(\mathrm{~d}, J=7.8 \mathrm{~Hz}$, $1 \mathrm{H}$ ), 7.15 (dd, $J=7.8 \mathrm{~Hz}, J=1.3 \mathrm{~Hz}, 1 \mathrm{H}), 6.99$ (td, $J=7.8$ $\mathrm{Hz}, J=1.3 \mathrm{~Hz}, 1 \mathrm{H}), 6.84(\mathrm{td}, J=7.8 \mathrm{~Hz}, J=1.3 \mathrm{~Hz}, 1 \mathrm{H})$, 3.95 (dd, $J=12.6 \mathrm{~Hz}, J=4.6 \mathrm{~Hz}, 2 \mathrm{H}$ ), 3.45 (t, $J=12.6 \mathrm{~Hz}$, 2H), 3.05 (td, $J=12.6 \mathrm{~Hz}, J=4.6 \mathrm{~Hz}, 2 \mathrm{H}), 1.88$ (d, $J=$ 12.6 Hz, 2H), 1.20 (s, 9H). ${ }^{13} \mathrm{C}$ NMR (125 MHz, DMSO- 
$\left.d_{6}\right) \delta 142.4,141.7,125.2,124.4,121.8,121.6,112.7,80.2$, 65.3, 54.7, 37.5, 30.5. LCMS m/z $291(\mathrm{M}+\mathrm{H})$. Anal. calcd for $\mathrm{C}_{16} \mathrm{H}_{22} \mathrm{~N}_{2} \mathrm{OS}$ : C, $66.17 \mathrm{H}, 7.64$; N, 9.65. Found: C, 66.22 H, 7.70; N, 9.71. 4e: Pale yellow solid, $\mathrm{mp}=181$ $183^{\circ} \mathrm{C}$. Single diastereomer! ${ }^{1} \mathrm{H}$ NMR (500 MHz, DMSO$\left.d_{6}\right) \delta 7.98(\mathrm{~s}, 1 \mathrm{H}), 7.88(\mathrm{~d}, J=7.8 \mathrm{~Hz}, 1 \mathrm{H}), 7.11(\mathrm{dd}, J=$ $7.8 \mathrm{~Hz}, J=1.3 \mathrm{~Hz}, 1 \mathrm{H}), 6.96$ (td, $J=7.8 \mathrm{~Hz}, J=1.3 \mathrm{~Hz}$, $1 \mathrm{H}), 6.81(\mathrm{td}, J=7.8 \mathrm{~Hz}, J=1.3 \mathrm{~Hz}, 1 \mathrm{H}), 2.52-2.60$ (m, 2H), 2.03 (d, $J=12.6 \mathrm{~Hz}, 2 \mathrm{H}), 1.81$ (d, $J=12.6 \mathrm{~Hz}, 2 \mathrm{H})$, 1.17-1.30 (m, 11H), 0.87 (s, 9H). ${ }^{13} \mathrm{C}$ NMR $(125 \mathrm{MHz}$, DMSO- $\left.d_{6}\right) \delta 143.0,141.7,124.8,121.6,121.2,113.8,82.7$, 54.6, 45.4, 37.5, 32.0, 30.6, 27.4, 24.8. LCMS m/z 345 $(\mathrm{M}+\mathrm{H})$. Anal. calcd for $\mathrm{C}_{21} \mathrm{H}_{32} \mathrm{~N}_{2} \mathrm{~S}$ : C, $73.20 \mathrm{H}, 9.36$; , 8.13. Found: C, 73.17 H, 9.34; N, 8.02. 4f: Beige solid, mp $=201{ }^{\circ} \mathrm{C}$ (decomp.). ${ }^{1} \mathrm{H}$ NMR (500 MHz, DMSO- $d_{6}$ ) $\delta 8.07(\mathrm{~s}, 1 \mathrm{H}), 7.42$ (d, $J=7.8 \mathrm{~Hz}, 1 \mathrm{H}), 7.23$ (d, $J=8.6$ $\mathrm{Hz}, 2 \mathrm{H}), 7.20$ (d, $J=7.8 \mathrm{~Hz}, 1 \mathrm{H}), 7.07$ (t, $J=7.8 \mathrm{~Hz}, 1 \mathrm{H}$ ), $6.93(\mathrm{~s}, 1 \mathrm{H}), 6.90$ (t, $J=7.8 \mathrm{~Hz}, 1 \mathrm{H}), 6.83(\mathrm{~d}, J=8.6 \mathrm{~Hz}$, 2H), $3.70(\mathrm{~s}, 3 \mathrm{H}), 1.12(\mathrm{~s}, 9 \mathrm{H}) .{ }^{13} \mathrm{C}$ NMR $(125 \mathrm{MHz}$, DMSO- $\left.d_{6}\right) \delta 158.8,143.6,140.4,134.6,127.4,127.0$, 125.6, 122.8, 122.4, 113.6, 111.2, 65.8, 55.2, 54.1, 30.6. LCMS m/z $327(\mathrm{M}+\mathrm{H})$. Anal. calcd for $\mathrm{C}_{19} \mathrm{H}_{22} \mathrm{~N}_{2} \mathrm{OS}$ : C, 69.90 H, 6.79; N, 8.58. Found: C, 70.03 H, 6.87; N, 8.65. (8) Crystallographic data (excluding structure factors) for the structures $4 \mathbf{f}$ and $\mathbf{5 a}$ have been deposited with the Cambridge Crystallographic Data Centre as supplementary publication numbers CCDC 774773 and CCDC 774774. Copies of the data can be obtained free of charge, on application to CCDC, 12 Union Road, Cambridge CB2 1EZ, UK [fax: +44(0)-1223-336033 or e-mail: deposit@ccdc.cam.ac.uk].

(9) (a) Saegusa, T.; Ito, Y.; Kobayashi, S.; Hirota, K.; Yoshioka, H. Tetrahedron Lett. 1966, 7, 6121-6124. (b) Smith, R.; Livinghouse, T. Synth. Commun. 1984, 14, 639646. (c) Hashida, Y.; Imai, A.; Sekiguchi, S. J. Heterocycl. Chem. 1989, 26, 9901-905. (d) Simon, J. R. Synthesis 2001, 2011-2014. (e) Cao, C.; Shi, Y.; Odom, A. L. J. Am. Chem. Soc. 2003, 125, 2880-2881. 


\section{o-Aminothiophenol in IMCR: a Word of Caution}<smiles>[R]C1([R])Nc2ccccc2S1</smiles>

10 examples

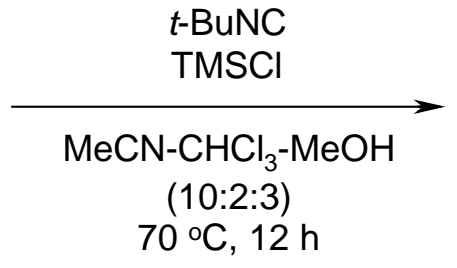

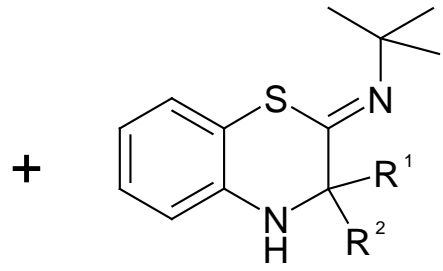

$0-38 \%$ 